\title{
Presentación libro Valores $y$ virtudes en medicina
}

\section{Book presentation: Values and virtues in medicine}

Muy buenas tardes y sean bienvenidos a la presentación del libro colectivo: Valores y Virtudes en Medicina. Agradezco su presencia y su interés para compartir algunas de las ideas contenidas en este libro con nuestros distinguidos presentadores.

Como se señala en la introducción del libro, la importancia del texto no puede exagerarse, el extraordinario desarrollo científico-tecnológico de los últimos cincuenta o sesenta años ha tenido también un fuerte impacto en las prácticas de la salud, especialmente en las médicas, Ilevando a una serie de dilemas que los médicos y en general el personal de salud deben enfrentar.

En el libro se abordan problemas filosóficos de alcance profundo, como la discusión de los valores y virtudes en la práctica clínica. También se discute si es verdad, como se dice, que el desarrollo científico-tecnológico ha llevado a una práctica médica deshumanizada, o si más bien son las instituciones, en general sobrecargadas de trabajo, especialmente las que ofrecen servicios gratuitos de salud, las que se han visto afectadas por esa deshumanización.

Se analiza también la importancia de los contextos culturales de donde provienen los pacientes, problema fundamental en un país como el nuestro, en el que, como sabemos, la décima parte de la población está conformada por pueblos indígenas, cuyas culturas son notablemente diferentes a la occidental dominante.

El concepto de dignidad no podía quedar fuera y varios capítulos en el libro abordan este concepto fundamental dentro de las prácticas de salud.

Ofrecer atención y servicios de salud dignos constituye un elemento fundamental de una sociedad justa. Otro capítulo analiza una de las concepciones de la justicia social más importante en los tiempos recientes: la del economista, filósofo y politólogo, Premio Nobel de economía, Amartya Sen.

También se destaca el papel del conocimiento tácito en las prácticas de salud. Cuestión de gran importancia porque muchas veces cuando se piensa en conocimiento, especialmente el que guía las prácticas médicas y de salud, se piensa sólo en conocimiento explícito; es decir, en el conocimiento que puede expresarse proposicionalmente y se suele dejar de lado el importantísimo conocimiento tácito, el cual, por definición, no puede hacerse manifiesto ni expresarse por medio de proposiciones. Gran parte del conocimiento que se transmite en la formación de nuevos médicos y del personal de apoyo en las prácticas de salud, es conocimiento tácito, que lo estudiantes aprenden mediante 
el ejemplo de sus maestros, y que difícilmente puede codificarse en algún tratado.

Otro capítulo versa sobre aspectos legales y la responsabilidad médica, haciendo hincapié en la situación mexicana. Y no menos importante, es la discusión sobre cómo pueden ensañarse los valores, para lo cual se discute el papel del cine.

La segunda parte del libro se centra en la dignidad humana y en el concepto de autonomía. Esto se discute en el caso de niños y también en el caso de pacientes geriátricos que en muchas ocasiones presentan problemáticas semejantes.

La tercera parte reúne una serie de estudios empíricos. Se abordan dilemas en la práctica clínica que enfrenta el personal de salud y se discuten también los dilemas éticos en cuidados paliativos, lo cual constituye uno de los extremos cuando ya no es posible hacer gran cosa por los pacientes.
El penúltimo capítulo aborda la problemática de la diversidad cultural, que como ya dijimos plantea una importante serie de problemas, en un país como el nuestro, donde están presentes numerosos grupos con una cultura propia y diferente a la dominante. Finalmente se discute la problemática de las políticas públicas en materia de salud.

Como pueden apreciar ustedes, todos los temas que se abordan en este libro son de gran importancia para la práctica médica y en general para las prácticas de salud.

De nueva cuenta les agradezco su interés y su presencia, y pasamos a escuchar a nuestros comentaristas especializados en diferentes campos de la salud y de la filosofía.

León Olivé Morett Instituto de Investigaciones Filosóficas, UNAM 